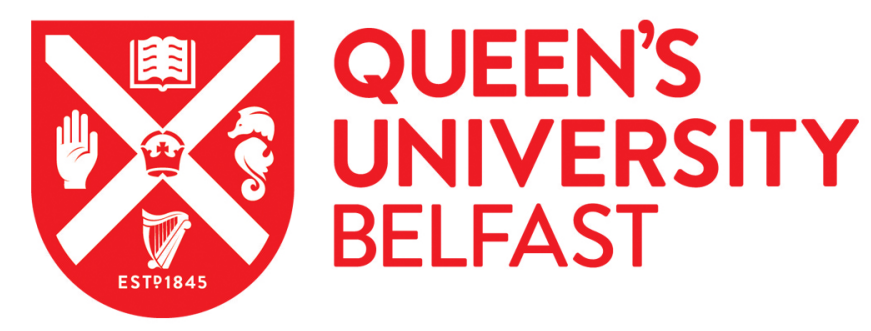

\title{
From global village to smart city: reputation, recognition, personalisation, and ubiquity
}

Mac Síthigh, D. (Accepted/In press). From global village to smart city: reputation, recognition, personalisation, and ubiquity. In U. Kohl, \& J. Eisler (Eds.), Data-driven Personalisation in Markets, Politics and Law Cambridge University Press.

\section{Published in:}

Data-driven Personalisation in Markets, Politics and Law

\section{Document Version:}

Early version, also known as pre-print

\section{Queen's University Belfast - Research Portal:}

Link to publication record in Queen's University Belfast Research Portal

\section{Publisher rights}

Copyright 2020 Cambridge University Press. This work is made available online in accordance with the publisher's policies. Please refer to any applicable terms of use of the publisher.

\section{General rights}

Copyright for the publications made accessible via the Queen's University Belfast Research Portal is retained by the author(s) and / or other copyright owners and it is a condition of accessing these publications that users recognise and abide by the legal requirements associated with these rights.

\section{Take down policy}

The Research Portal is Queen's institutional repository that provides access to Queen's research output. Every effort has been made to ensure that content in the Research Portal does not infringe any person's rights, or applicable UK laws. If you discover content in the Research Portal that you believe breaches copyright or violates any law, please contact openaccess@qub.ac.uk. 


\section{From global village to smart city: reputation, recognition, personalisation, and ubiquity}

Daithí Mac Sithigh*

July 2020

\section{Introduction}

'Smart city' projects today range from a proposed (and now abandoned) redevelopment of a waterfront site in Canada, infused with sensors and automated systems, to 'pilot cities' in China, utilising the rating of citizens as a key tool of governance, to multiple cities in the UK that are, as part of 'city deals' with central and devolved governments, building testbeds, innovation districts, and digital strategies. Across these and other projects, and distinguishing current developments from an earlier wave with more of a focus on city operations, new ways of delivering personalised services to people, including residents, are being explored. But what are the guiding principles governing these initiatives, and what motivates their proponents?

How the individual navigates and engages with the smart city has long been a concern in science fiction. Philip K. Dick's The Minority Report, a mid-20 $0^{\text {th }}$ century short story, was the basis for a turn-of-the-century film of almost the same title, containing production designer Alex McDowell's vivid depictions of facial and retina identification, and - famously - personalised (and contextual) advertising utilising audio, video, holographic projections, and interactivity of various sorts. ${ }^{1}$ More recently, a 2016 episode of the series Black Mirror imagined a world where we rate every interaction we have with other people, and that this information (overlaid on our view of the world, in the style of augmented reality), drives our social standing, our access to markets, and even our freedom. ${ }^{2}$

Presently, we see cities around the world trying to set standards for their digital agendas, and constructing smart city 'roadmaps'. They confront a set of shared challenges: whether to emphasise the power of aggregate data or the delivery of personalised services; whether to seek the most innovative technology or focus on interventions with the greatest impact on quality of life; whether to prioritise improving the work that public authorities already do, or facilitate experimentation and the emergence of new products and services, or a new role for, the private sector.

I explore these tensions in this chapter, taking stock of emerging approaches that seek to apply or supplement existing rules on privacy and data protection and to sustain public confidence and support in the face of innovation and change. First, I situate this work in the context of new waves of smart city projects, and the growing critical literature, in law, planning, and other fields, that seeks to identify the nature and

\footnotetext{
*Professor of law and innovation, Queen's University Belfast; d.macsithigh@qub.ac.uk. This is a preprint of a chapter which will be published in revised form in Uta Kohl and Jacob Eisler (eds), DataDriven Personalisation in Markets, Politics and Law (Cambridge University Press).

${ }^{1}$ Minority Report (dir. Stephen Spielberg) $\left(20^{\text {th }}\right.$ Century Fox, 2002); for the original story, see Philip K Dick, 'The Minority Report' (1956).

2 'Nosedive' (S3E1).
} 
implications of these initiatives, beyond the promotional language of 'smart'. With these developments highlighting important tensions between public and private sector approaches, I then highlight the work of Sidewalk, a Google-affiliated company, which articulated various iterations of its masterplan for a site in Toronto, engaging in significant debates on data ownership, surveillance, and intellectual property, and of the Los Angeles Department of Transportation, which developed a new and influential approach to mobility data (data associated with ridesharing, 'micromobility' such as escooters, and in time autonomous vehicles), responding to technological and market change in a field with significant environmental, quality of life, and privacy implications.

Then, I explore two facets of urban technology that relate to (and ultimately enable) the delivery of personalised services by public authorities and others. The first is ratings and reputation, where I highlight Chinese cities deploying aspects of the emerging 'social credit' systems, building upon the prevalence and acceptability of reputation measurement that dates back to credit scoring. Indeed, reputation is at the heart of many features of Western digital markets, including online auctions and the sharing economy, but is taking on a new role, supported by the pervasiveness and interconnectedness of surveillance, in service delivery. The second is facial recognition, which is currently being reviewed in light of data protection law, human rights requirements, public policy concerns, and discrimination; the ability to recognise individuals in this way, without a conventional and more deliberate identification (e.g. supplying a name, entering a password, or older biometric systems such as fingerprint scanning), is a key part of many proposed personalised services.

\section{Evolving concepts of the smart city}

It is expected that two-thirds of the world's population will live in a city by $2050 .^{3}$ In planning for this, public authorities (and their private sector partners) are already addressing increasing urban populations, the delivery of services at scale, changing patterns of living (multi-occupancy units, 24-hour activity), conflicts over natural resources and shared spaces, and more. So, work that falls under the broad 'smart city' label, especially that which seeks to manage the relationship between the responsible authority and individual residents or other users (visitors, workers, etc), is happening in a context where new technologies can and should be assessed in terms of how well they address these existing and increasingly urgent questions of policy and planning.

These plans and innovations in urban planning often aim to address the most salient problems facing society, globally and locally. For example, as plans and strategies have proliferated, an emphasis upon (environmental) efficiency and sustainability has emerged. So, for example, the 2017 Digital Strategy adopted by the Scottish Government takes as a working definition for smart cities that they encompass 'a way of using digital technologies to manage resources and infrastructure in a sustainable way, making our cities more efficient and greener places to live and do business'. ${ }^{4}$ This, of course, builds upon long-standing visions of how the use of digital technologies and services affects the relationship between the citizen and the city:

\footnotetext{
${ }^{3}$ Robert Kunzig, 'Rethinking cities' (2019) 235(4) National Geographic 70.

${ }^{4}$ Scottish Government, 'Digital Strategy Evidence Discussion Paper' (2017)

https://www.gov.scot/publications/scotlands-digital-strategy-evidence-discussion-paper/ 11.
} 
Imagine life for the citizen of the smart city: you awake in your sustainably built home ... eating breakfast, you scan the flat screen, fed by maximum bandwidth internet, where the special, easy click local neighbourhood menu allows you to compare your daily energy use with other houses in the area, confirm your webcam appointment with your doctor, top up the balance of your all-purpose travelcard, order your groceries and leave messages for your child's teacher. ${ }^{5}$

This particular depiction, dating from 2010, is found in some of today's cities (and has become more familiar in 2020 on account of restrictions on movement imposed in response to Covid-19). ${ }^{6}$ Yet as vision becomes reality, for better or for worse, the complexities of the citizen-city relationship in a technological context still need to be addressed. In particular, the possibility of using information, and either the digital delivery of that information to the individual, or its use in the background in order to present a different path to said individual, is likely to be controversial. As Cobbe and Morison put it in discussing informational asymmetries, bodies (including local government) seek to 'influence behaviour ... according to the rationalities of efficiency, sustainability, and participation', through everything from personalised/differentiated pricing to sending notifications to smartphones, and (at macro level) routing and movement control. They therefore summarise life in the smart city, for the citizen who is also conceived of as consumer, as 'a process of perpetual choice-making'. ${ }^{7}$

$21^{\text {st }}$-century innovations, both in urban renewal more generally and in media and information industries, often address 'pseudo-public' spaces. ${ }^{8}$ Examples include open squares constructed within private developments, city centre revitalisation projects, online communities, and search engines. In these 'pseudo-public' spaces, it is particularly likely that the rights of and basis for authority over individuals is ambiguous, or there is a tension between the presentation of the space and the prevailing legal conditions. For instance, various aspects of contract or property law may be the basis for broader governance of behaviour.

Smart city initiatives encapsulate this ambiguity by creating a 'smart' urban space, likely to be a hybrid of virtual and material, ${ }^{9}$ and so deserving of analysis that goes beyond parallels or analogies between e.g. a town square and an online discussion board. Edwards observes that some of these new spaces are pseudo-private, where what is historically and unquestionably public is becoming 'privately operated or at least full of privately operated sensors with the data collected held in private

\footnotetext{
5 Terry Kirby, 'City design: Transforming tomorrow' (The Guardian (online), 8 September 2010).

${ }^{6}$ Aamer Baig and others, 'The COVID-19 recovery will be digital' (McKinsey, 14 May 2020) https://www.mckinsey.com/business-functions/mckinsey-digital/our-insights/the-covid-19-recoverywill-be-digital-a-plan-for-the-first-90-days.

${ }^{7}$ Jennifer Cobbe and John Morison, 'Understanding the Smart City: Framing the challenges for law and good governance' in Jean Bernard Auby, Émilie Chevalier and Emmanuel Slautsky (eds), Le Futur de Droit Administratif / The Future of Administrative Law (LexisNexis 2019).

${ }^{8}$ Daithí Mac Síthigh, 'Virtual walls? The law of pseudo-public spaces' (2012) 8 International Journal of Law in Context 394.

${ }^{9}$ See e.g. Hilton's argument, after Carlo Ratti, that the availability of ubiquitous computing influences the design of physical spaces: Steve Hilton, More Human: Designing a World Where People Come First (Ebury 2015) 269. For a more fundamental argument (on spatial approaches to software), see Rob Kitchin and Martin Dodge, Code/space: Software and Everyday Life (MIT Press 2011); for an application of the code/space theory in a smart city context, see e.g. Rob Kitchin, 'From a single line of code to an entire city: reframing the conceptual terrain of code/space' in Rob Kitchin and SungYueh Perng (eds), Code and the city (Routledge 2016).
} 
databases'. ${ }^{10}$ Similarly, Green emphasises how the 'smart city is a dream come true' for those who have perfected online data collection, but see new opportunities in physical space. ${ }^{11}$ So, the types of regulatory measure (including user rights) available will vary across new schemes and services in cities - and so the starting points and doctrinal 'homes' for oversight of personalised services will vary as well.

Brauneis and Goodman, writing about the Toronto project discussed below, ask questions of the governance models, identifying the importance of access and ownership to data and the analysis thereof, control over physical infrastructure, and so 'whether public entities will be able to take control of the informational and physical assets should they wish to end the relationship with the private company'. ${ }^{12}$ Even in contexts where private sector activity is the subject of a general regulatory regime, as under EU data protection law, the emergence of projects like in-store tracking highlights the varying relevance of legal safeguards that only impact some classes of actors, as well as the potential ineffectiveness of the mitigation measures that might be deployed in other contexts (e.g. privacy-enhancing technologies or 'do not track'style settings). ${ }^{13}$

These questions, about understanding the regulatory constraints on components of the smart city, also bring us back to the role of data analytics in the delivery of personalised services. ${ }^{14}$ Yeung's distinction between 'static nudges' and 'hypernudges' helps us to understand these implications. ${ }^{15}$ While the typical static nudge - a fashionable and controversial aspect of $21^{\text {st }}$ century public policy - is based on the organising party's ability to design an intervention in order to deploy it for a particular end ${ }^{16}$ (e.g. the spatial organisation of a cafeteria in order to promote healthy choices), hypernudges are formulated in light of data analysis and, in particular, 'continuously updated'. ${ }^{17}$ The allure of such approaches is clear. For instance, research conducted regarding social media use showed how the consideration of behaviour (i.e. reading history) and network analysis (i.e. shared interests) provided

\footnotetext{
${ }^{10}$ Lilian Edwards, 'Privacy, Security and Data Protection in Smart Cities: A Critical EU Law Perspective' (2016) 2 European Data Protection Law Review 28.

${ }^{11}$ Ben Green, The Smart Enough City: Putting Technology in Its Place to Reclaim Our Urban Future (MIT Press 2019) 99.

${ }^{12}$ Robert Brauneis and Ellen Goodman, 'Algorithmic transparency for the smart city' (2018) 20 Yale Journal of Law and Technology 103.

${ }^{13}$ Vasilios Mavroudis and Michael Veale, 'Eavesdropping Whilst You're Shopping:

Balancing Personalisation and Privacy in Connected Retail Spaces' Living in the Internet of Things: Cybersecurity of the loT https://ieeexplore.ieee.org/document/8379705.

${ }^{14}$ See further Sofia Ranchordás and Abram Klop, 'Data-Driven Regulation and Governance in Smart Cities' in Vanessa Mak, Eric Tjong Tjin Tai and Anna Berlee (eds), Research Handbook in Data Science and Law (Edward Elgar 2018).

${ }^{15}$ Karen Yeung, '“Hypernudge”: Big Data as a mode of regulation by design' (2016) 20 Information, Communication \& Society 118.

${ }^{16}$ Richard Thaler and Cass Sunstein, Nudge: Improving Decisions about Health, Wealth, and Happiness (Yale University Press 2008); Muireann Quigley, 'Nudging for health: on public policy and designing choice architecture' (2013) 21 Medical Law Review 588; Christopher McCrudden and Jeff King, 'The dark side of nudging: the ethics, political economy, and law of libertarian paternalism' in Alexandra Kemmerer and others (eds), Choice Architecture in Democracies, Exploring the Legitimacy of Nudging (Hart 2016).

17 Yeung (n 15) 122.
} 
'better performance' than allowing users to customise their own settings. ${ }^{18}$ On the other hand, particular types of targeting may raise a version of the famous 'uncanny valley' problem in robotics, ${ }^{19}$ whereby a certain measure of automation is convenient and appealing, but a particular level of 'imitation' of (e.g.) human behaviour can provoke distrust and even fear or disgust. So where a city proposes or facilitates a new relationship with individuals (such as the project in Nice to provide customised advice on skin protection in light of skin type and real-time UV data ${ }^{20}$ ), feasibility and lawfulness are accompanied by important discourses of acceptability and impact.

Many of these interventions benefit from being understood not just as new ways of gathering and using data, but as 'social mediation technologies' - other examples of which include clocks, cars, and mobile phones. ${ }^{21}$ These technologies cannot be understood as only concerning personal choices, given their implications for others and in the organisation of social life. So, for instance, the use of a mobile phone does not just affect the user - it reshapes their social interactions with their contacts (everything from whether to set a meeting time and place, to how decisions, including those with legal implications, are made), as well as the obvious changes in shared physical spaces when disparate individuals bring or use the devices.

The link between the opacity of some of the technological developments and services mentioned in this section, and their implications for individuals and for social relations, is appropriately highlighted in a broader context by Bridle. He identifies a proclivity to think computationally and so consider new technologies as 'inherently emancipatory.'22Similarly, Morozov describes the 'solutionism' applied by technology companies, and their admirers in public service, to long-established social and economic problems. ${ }^{23}$

Having outlined some of the dilemmas and challenges facing developers of innovative projects in cities more generally, we can now illustrate these by considering a specific (and very controversial) project in one city (Sidewalk Toronto), followed by an initiative developed in another city but being adopted elsewhere (the Los Angeles 'Mobility Data Specification'). These debates highlight a crucial challenge for data-informed and data-driven approaches to city governance - developing against a backdrop of a quarter-century of public-private partnerships and other administrative

\footnotetext{
18 Tuck Siong Chung, Michel Wedel and Roland Rust, 'Adaptive personalization using social networks' (2015) 44 Journal of the Academy of Marketing Science 66.

${ }^{19}$ Ashesh Mukherjee, The internet trap: five costs of living online (University of Toronto Press 2018) 51; for the original, see Masahiro Mori, Karl MacDorman and Norri Kageki, 'The Uncanny Valley' (2012) 19 IEEE Robotics \& Automation 98; for recent applications in legal and policy contexts, see e.g. Jeannie Suk Gersen, 'Sex lex machina' (2019) 119 Columbia Law Review 1793; Sulaf Al-Saif, 'Animal Healthcare Robots: The Case for Privacy Regulation' (2019) 14 Washington Journal of Law, Technology \& Arts 77; Eric Gerson, 'More Gore - Video Game Violence and the Technology of the Future Note' (2010) 76 Brooklyn Law Review 1121.

${ }^{20}$ Marie Veltz, Jonathan Rutherford and Antoine Picon, 'Smart urbanism and the visibility and reconfiguration of infrastructure and public action in the French cities of Issy-les-Moulineaux and Nice' in Andrew Karvonen, Federico Cugurullo and Federico Caprotti (eds), Inside smart cities: place, politics and urban innovation (Routledge 2019) 141.

${ }^{21}$ Richard Seyler Ling, Taken for grantedness : the embedding of mobile communication into society (MIT Press 2012).

22 James Bridle, New dark age : technology and the end of the future (Verso 2018) 3-4.

${ }^{23}$ Evgeny Morozov, To Save Everything, Click Here (Penguin 2013) ch 1.
} 
developments ${ }^{24}$ - of how to proceed in contexts where ownership and control spans the public and private sectors.

\section{Smart cities and the public/private divide}

\subsection{Sidewalk Toronto}

The planned Sidewalk Toronto development, which was discontinued in May 2020, can be understood as a good illustration of the implications of planned 'smart city' development. Sidewalk Labs is a subsidiary of Alphabet (Google's holding company), and followed some initial projects based around specific technologies with a larger and more ambitious project - a demonstrator or examplar urban neighbourhood of the future, to be built on a parcel of land held by the waterfront redevelopment authority in the Canadian city of Toronto. On what a newspaper called 'twelve acres of unsightly, soggy Toronto waterfront real estate', ${ }^{25}$ Sidewalk sought to put into practice its mission statement of 'reimagining cities to improve quality of life', but faced multiple and sustained criticisms on issues including privacy, data control and ownership, and the use of public spaces and public resources. ${ }^{26}$ The key documents in the Sidewalk Toronto project, relevant to the present analysis, include a 'master innovation and development plan' (2018-19), ${ }^{27}$ reports from Waterfront Toronto's 'digital strategy advisory panel' (2019-20), ${ }^{28}$ and a 'digital innovation appendix' (late 2019) ${ }^{29}$ setting out specific approaches to questions such as data protection.

What was first proposed for Sidewalk - making it, in its own phrase, 'the most measurable community in the world'30 represents what Hollands called, writing prior to the specific projects being discussed here, the ubiquitous city, with technology, especially sensors for data collection, embedded in its fabric. ${ }^{31}$ A subsequent assessment of breakthrough technologies published in the MIT Technology Review

\footnotetext{
${ }^{24}$ Rob Kitchin, 'Data-driven urbanism' in Rob Kitchin, Tracey Lauriault and Gavin McArdle (eds), Data and the city (Routledge 2018) 51.

${ }^{25}$ Josh O'Kane, 'Sensor city: Google project triggers debate over data' The Globe and Mail (Toronto, 24 February 2018) B1.

${ }^{26}$ This is well documented in a number of recent publications, including Ellen Goodman and Julia Powles, 'Urbanism under Google: lessons from Sidewalk Toronto' (2019) 88 Fordham Law Review 457; Sofia Ranchordás and Catalina Goanta, 'The New City Regulators: Platform and Public Values in Smart and Sharing Cities' (2019) 20 Computer Law \& Security Review; Green (n 11) ch 7.

${ }^{27}$ In multiple volumes; for the overview, see https://storage.googleapis.com/sidewalk-toronto-ca/wpcontent/uploads/2019/06/23135500/MIDP Volume0.pdf.

${ }^{28}$ For the 2019 preliminary report, see

https://waterfrontoronto.ca/nbe/wcm/connect/waterfront/30c682ff-8172-49dc-bf63-

09b2a2f1845a/DSAP+Preliminary+Commentary+-+September+10\%2C+2019.pdf; see also the supplementary report at https://waterfrontoronto.ca/nbe/wcm/connect/waterfront/521b1d08-34994a49-9d2c-b5fc34990ce5/DSAP+Report+\%2B+Appendices.pdf.

${ }^{29} \mathrm{https}: / /$ storage.googleapis.com/sidewalk-toronto-ca/wpcontent/uploads/2019/11/15093613/Sidewalk-Labs-Digital-Innovation-Appendix.pdf.

${ }^{30}$ Tom Knowles, 'Google sets sights on Toronto as its city of the future' The Times (London, 27 November 2018).

${ }^{31}$ Robert Hollands, 'Critical interventions into the corporate smart city' (2015) 8 Cambridge Journal of Regions, Economy and Society 61.
} 
described Sidewalk as an example of the 'sensing city.'32 Indeed, the early plans for Sidewalk Toronto included a proposed 'data layer', combining an established trope in $20^{\text {th }}$ century utopian and urban renewal design, of rethinking the city through its vertical layers (e.g. separating utilities from pedestrians from traffic, as in famous $20^{\text {th }}$ century projects ranging from university campus like the University of East Anglia to the unbuilt Experimental City in Minnesota) ${ }^{33}$ with the centrality of layering to Internet infrastructure. ${ }^{34}$

Reports on the plans understandably emphasised the significance of the data layer to the achievement of the project's goals. One report by writer Laura Bliss, who followed the project closely through its development, utilised footfall, building occupancy, energy use, and the contents of rubbish bins as examples, making an explicit link to Sidewalk's own correlation of measurement with better management, and the abovementioned 'most measurable community' goal. ${ }^{35}$ In their detailed analysis of Sidewalk's documentation and negotiations, Goodman \& Powles identified how the technologies planned for deployment, and how they would interact with the delivery of services, utilise 'hypernudge' approaches in order to regulate land use and resident behaviour in an effective fashion.

In the later stages of the project, Sidewalk emphasised 'quality of life' as the key innovative contribution of the project, highlighting features like streetscapes that adapted to weather conditions (including matters dear to the Torontonian's heart, like paving slabs that would detect and melt snow where appropriate). ${ }^{36}$ In a 2019 update, Sidewalk emphasised aggregation (e.g. tracking footfall) and improving services at the general level (e.g. 'self-driving' refuse bins), noting that a majority of services would not engage with personal data, and swearing off the use of facial recognition. ${ }^{37}$

Yet the difference between 'normal' urban space and what Quayside would look like has been a feature of debate, throughout; the governance implications of such, as outlined in the above discussion of pseudo-public and pseudo-private spaces, are significant. As one headline from the Canadian public broadcaster put it, echoing a familiar objection to digital and online services: 'welcome to the neighbourhood; have you read the terms of service?'38 For Goodman and Powles, proposals like the of 'smart chutes' in apartment buildings (which would differentiate between recyclable

\footnotetext{
${ }^{32}$ MIT Technology Review (January/February 2018).

${ }^{33}$ John Sutton, Gridlock: Congested Cities, Contested Policies, Unsustainable Mobility (Taylor \&

Francis 2015) 137ff (concept); Basilio Tobias, 'Urban Projects and Megastructures: Modernist

Campuses' in Carmen Díez Medina and Javier Monclús (eds), Urban Visions: from planning culture to landscape urbanism (Springer 2018) (campus design); Peter Dormer and Stefan Muthesius, Concrete and open skies (Unicorn 2001) 74 (East Anglia); The Experimental City (dir. Chad Freidrichs) (Unicorn Stencil, 2017) (Minnesota).

${ }^{34}$ Lawrence Lessig, Code v 2.0 (Basic Books 2006) ch 4.

${ }^{35}$ Laura Bliss, 'How Smart Should a City Be? Toronto Is Finding Out' (CityLab, 7 September 2018) https://www.bloomberg.com/news/articles/2018-09-07/what-s-behind-the-backlash-over-sidewalklabs-smart-city.

$36 \mathrm{lbid}$

${ }^{37}$ Moira Warburton, 'Sidewalk Labs' Toronto smart city to feature self-driving garbage cans, apartment noise monitors' National Post (Toronto, 16 November 2019); Digital Innovation Appendix (n 29).

${ }^{38}$ Matthew Braga, 'Welcome to the neighbourhood. Have you read the terms of service?' (CBC News, 16 January 2018) https://www.cbc.ca/news/technology/smart-cities-privacy-data-personal-informationsidewalk-1.4488145.
} 
waste on one hand and refuse destined for landfill on the other) calls into question control over data (which would be collected through Sidewalk's infrastructure). From this, they ask whether innovation of this nature relates to or potentially marginalises the broader role of competent public authorities, who might wish to take data-driven approaches to their functions but would rely upon the private sector for access to key data. $^{39}$

As the project developed, we can note how the responsible authority (Waterfront Toronto) began to articulate the public policy goals that technological innovation would address more clearly. In its 2018 'priority outcomes' it explained its desired outcomes as employment/economic development, affordable housing, sustainability, mobility, and urban innovation; ${ }^{40}$ Sidewalk itself subsequently explained its plans under these headings, ${ }^{41}$ though Waterfront Toronto's digital strategy advisory panel thought that the plan contained too much 'tech for tech's sake'. ${ }^{42}$ This is consistent with Cobbe and Morison's identification of the recurrent themes found in the 'goals' of smart city projects, or the 'problems' that they seek to address: competitiveness, efficiency, sustainability, and (challenging) top-down governance ${ }^{43}$ - though the governance questions in relation to Sidewalk, especially whether it would perform functions in substitution for local government, or be beyond scrutiny, drew particularly sustained objections. ${ }^{44}$ One question left unanswered (echoing the Morozov critique of solutionism) is whether criticism of the project can be characterised as an objection to the selection of problems, or an acceptance of the problems while being dissatisfied with the solutions. As such, even though the systems will not be built (at least in Toronto) as planned, the record of adaptation and reframing on the part of the various partners, and the way in which objectives and use cases were, over time, documented in more detail, is of enduring significance.

\subsection{Mobility data}

The role of the individual in the networked or ubiquitous city is also called into question in the case of new transport or mobility services. Here, too, we see the articulation of a problem and the presentation of solutions aided by new technologies. Tackling congestion and associated environmental harm has long been a key goal for planners and those concerned with future cities, ${ }^{45}$ and visually represented, or at least imagined, in everything from jetpacks ${ }^{46}$ to hoverboards ${ }^{47}$ - and, in Minority Report,

\footnotetext{
${ }^{39}$ Goodman and Powles (n 26) 487.

${ }^{40}$ Waterfront Toronto, 'Realising the Waterfront's Potential' (December 2018) https://quaysideto.ca/wp-content/uploads/2019/04/Evaluation-and-Objectives Draft Dec82018.pdf. 41 MIDP (n 27) $162 f f$.

42 Digital Strategy Advisory Panel, preliminary commentary (n 28); cf Amy Fleming, 'The case for ... making low-tech 'dumb' cities instead of 'smart' ones' The Guardian (15 January 2020) https://www.theguardian.com/cities/2020/jan/15/the-case-for-making-low-tech-dumb-cities-instead-ofsmart-ones.

${ }^{43}$ Cobbe and Morison ( $\mathrm{n} 7$ ).

${ }^{44}$ Goodman and Powles (n 26) pt IIB.

${ }^{45}$ See for instance Sutton (n 33); though as Bertaud notes, there was no golden age, and Roman authors bemoaned recognisable challenges in the ancient city: Alain Bertaud, Order without Design: How Markets Shape Cities (MIT Press 2018) 158.

${ }^{46}$ Daniel Wilson, Where's my jetpack? a guide to the amazing science fiction future that never arrived (Bloomsbury 2007).

47 Back to the Future: part II (dir. Robert Zemeckis) (Universal Pictures, 1989); see also Jonah Engel Bromwich and Daniel Victor, 'Why a "Back to the Future" Hoverboard Never Took Off' New York
} 
autonomous cars. For 'smart mobility' to have a positive impact, it is essential - as Docherty and co-authors have argued - to address questions of governance, so as to avoid a situation where new technologies are deployed in a way that makes the abovementioned problems worse rather than better. ${ }^{48}$

Of particular relevance in this chapter is the fact that new forms of mobility, including ridesharing, 'micromobility' (e.g. electric scooters), and in time autonomous vehicles of various sorts, have a set of data flows built into their design; this facilitates location and pricing, in the first instance, but offer the potential for dynamic management of how spaces (including roads) are used, as well as providing better, real-time 'multimodal' information on transport and other options to individuals.

Building upon the experiences of regulating the sharing economy (ridesharing in particular), and schemes such as docked or dockless bike rentals (as well as, in some cases, established procedures whereby commercial activity or the placing of property in public spaces requires permission), many US cities are now operating systems whereby scheme operators must obtain a licence or permit from city authorities. Increasingly, such systems also seek to address data issues. This is illustrated by an influential, open-source Mobility Data Specification (MDS), first developed by the City of Los Angeles, and now managed by a broader Open Mobility Foundation, with a number of industry participants. ${ }^{49}$ The use of MDS is a requirement of permits to operate e-scooter rental schemes in Los Angeles and a number of other US cities.

In early iterations, the focus was on API-enabled transfer of data from service providers to the city, though it now also includes certain functionality for data going in the other direction. MDS has provoked a broad discussion of the appropriateness of data sharing and of the implications of any decision on data for the future of mobility and city planning. There has been criticism of MDS and of data sharing requirements, including from some of the companies providing services, often citing the privacy of users as a concern; this has included challenges to the lawfulness of city-imposed requirements for data sharing. ${ }^{50}$ In response, city officials have collaborated on good practice guidance for mobility data, ${ }^{51}$ although legislative change (which would allow

\footnotetext{
Times (New York, 21 October 2015) https://www.nytimes.com/2015/10/22/business/why-a-back-tothe-future-hoverboard-never-took-off.html.

48 lain Docherty, Greg Marsden and Jillian Anable, 'The governance of smart mobility' (2018) 115 Transportation Research Part A: Policy and Practice 114.

${ }^{49}$ Ashley Hand, 'Urban mobility in a digital age: a transportation technology strategy for Los Angeles' (2016)

https://static1.squarespace.com/static/57c864609f74567457be9b71/t/57c9059b9de4bb1598eeee49/1 472793280502/Transportation+Technology+Strategy 2016.pdf; for the specification itself, see https://github.com/CityOfLosAngeles/mobility-data-specification/wiki; for the new governance model adopted in 2019, see https://www.openmobilityfoundation.org.

${ }^{50}$ Center for Democracy \& Technology, 'Comments to LADOT on Privacy \& Security Concerns for Data Sharing for Dockless Mobility' (29 November 2018) https://cdt.org/insight/comments-to-ladot-onprivacy-security-concerns-for-data-sharing-for-dockless-mobility/; Aarian Marshall, 'Why Uber Is Fighting Cities Over Data About Scooter Trips' (Wired, 13 May 2019)

https://www.wired.com/story/why-uber-fighting-cities-data-about-scooters/; Alfred Ng, 'Uber in talks with Los Angeles as scooter location data lawsuit looms' (CNET, 30 October 2019) https://www.cnet.com/news/uber-in-talks-with-los-angeles-as-scooter-location-data-lawsuit-looms/. 51 For instance, the National Association for City Transportation Officials (NACTO) (a North American organisation) principles on 'managing mobility data', identifying core principles (data as a public good, data protection, purposeful collection, and portability), and advising cities to reserve the right to 'share
} 
cities to require some data, but only in accordance with said legislation) is under consideration in some US states. ${ }^{52}$

The management of mobility data thus addresses this theme of how conventionally understood public functions, especially in terms of relationships with individuals, comes under challenge. The initial relationship, for instance, may be between the person who rents an e-scooter for ten minutes, or calls a rideshare car through an app as part of their commute, and the relevant service provider or platform. But the job of the city, or a public transport authority, includes managing use conflicts, understanding footfall and traffic, and - potentially - directing users in real time, providing neutral and comprehensive options on different modes, or coordinating the activities of disparate (and perhaps licensed) service providers.

So, as in other areas, we see the actual 'service', as narrowly defined, being delivered by private actors in a regulated market. But in the specific case of mobility, we also ascertain a broader concept of a relationship between the individual and the city that begins to feel like a service (possibly but not necessarily personalised). Commitments to 'mobility as a service' (MaaS) in a number of strategies underline these trends. ${ }^{53}$ Making this work is very likely to require data sharing in various ways. Yet, the issues regarding personal data are significant, but a remedy of aggregation and decontextualization may only facilitate certain uses (e.g. research, trends) and not others (e.g. trip planning, interoperability, integration with other public services) ${ }^{54}$

\section{Challenges in personalised services}

\subsection{Ratings and reputation}

The infamous Social Credit System (or systems) currently under development in China represents an elaborate illustration of the coming to prominence of rating and reputational systems utilising digital information and a wide range of infrastructure, and so the associated legal and other controls that would govern the calculation and utilisation of, and challenges to, 'scores', blacklists, and other initiatives. ${ }^{55}$

\footnotetext{
data with third-party researchers/organizations to fulfill planning, research, regulatory, or compliance needs', but also emphasising the importance of treating geospatial trip data as personally identifiable information with appropriate safeguards: NACTO, 'Managing mobility data' (2019)

https://nacto.org/wp-content/uploads/2019/05/NACTO IMLA Managing-Mobility-Data.pdf; NACTO,

'Guidelines for regulating shared micromobility' (2019) https://nacto.org/wpcontent/uploads/2019/09/NACTO Shared Micromobility Guidelines Web.pdf 31.

52 Joe Fitzgerald Rodriguez, 'State bill taking aim at city bikeshare, scooter regulations stalls in Senate' San Francisco Examiner (San Francisco, 3 July 2019) https://www.sfexaminer.com/thecity/state-bill-taking-aim-at-city-bikeshare-scooter-regulations-stalls-in-senate/.

${ }^{53}$ Department for Transport, Future of mobility: urban strategy (2019); House of Commons Transport Committee, Mobility as a Service (HC 590, 2017-19).

${ }^{54}$ See further Teresa Scassa, 'Navigating Legal Rights in Spatial Media' in Rob Kitchin, Tracey Lauriault and Matthew Wilson (eds), Understanding spatial media (Sage 2017).

${ }^{55}$ I draw here upon my own earlier work (with Mathias Siems), in which we explore the SCS, and rating and reputational systems in more detail: Daithí Mac Síthigh and Mathias Siems, 'The Chinese Social Credit System: A Model for Other Countries?' (2019) 82 The Modern Law Review 1034; on China, see also Kai Strittmatter, We Have Been Harmonised: Life in China's Surveillance State (Ruth Martin tr, Old Street 2019) ch 9; Rogier Creemers, 'China's Social Credit System: An Evolving Practice of Control' (2018) <https://dx.doi.org/10.2139/ssrn.3175792> ; Fan Liang and others, 'Constructing a Data-Driven Society: China's Social Credit System as a State Surveillance Infrastructure' (2018) 10 Policy \& Internet 415.
} 
Reputational systems have developed over the course of centuries, facilitated by technological developments (such as the ability to link databases), the presence or absence of legal measures, and commercial practices. So there is a thread running from the development of consumer credit rating (which has a significant reputational dimension) as capitalism expanded west in the United States in the 19th century, to how computers standardised and expanded this in the 20th, to the significance of trust to the success of eBay, the centrality of ratings to the sharing economy business models, and the exploring of alternatives to conventional credit scoring that is still going on today (such as taking signals from social media history and/or networks as an indication of creditworthiness) - not to mention unusual projects like a dating service based around credit scores. ${ }^{56}$ Indeed, we are increasingly reliant upon rating or reputational measures, e.g. in ecommerce or sharing economy markets with unfamiliar sellers or service providers - but there are significant questions regarding data protection law, the power of platforms, and discrimination. ${ }^{57}$

Meanwhile, the Chinese government has sought to build what has been termed a 'Social Credit System'. While a number of systems operate under this label, they have in common attempts to measure and 'score' sincerity, honesty, integrity, and compliance, and have some association with the regulation of individual behaviour and freedom (often through integration with existing legal measures, such as prioritisation in access to services). They resemble, but go beyond, more established rating and reputational systems by taking into account a wider range of factors (or, to put it differently, drawing upon more datasets) and by operating across contexts; the involvement of the state, and therefore the potential for systems to be allencompassing without the ability to opt out, is also more significant than many earlier systems developed in the (Western) private sector for use with existing customers.

The most relevant instances for this chapter are where social credit systems manage the relationship between the individual and, say, the public authority responsible for managing city life. Social credit systems in China include China-wide blacklists, compliance scores by pilot cities, and social credit scores issued by financial institutions. ${ }^{58}$ The first of these is a readily understandable list of those who have not complied with court judgments, though has been expanded and is particularly noteworthy when it involves co-operation with financial institutions. The second is more closely tied to surveillance, and is found in systems such as that in Rongcheng where 'points' are added and subtracted on account of behaviour, with implications for

\footnotetext{
${ }^{56}$ See Josh Lauer, Creditworthy : a history of consumer surveillance and financial identity in America (Columbia University Press 2017) $\left(19^{\text {th }}\right.$ and $20^{\text {th }}$ century consumer credit scoring and rating); Rachel Botsman and Roo Rogers, What's mine is yours : how collaborative consumption is changing the way we live (Collins 2011), Michael Fertik, The Reputation Economy: How to Optimise Your Digital Footprint in a World Where Your Reputation Is Your Most Valuable Asset (Little, Brown 2015) (both regarding consumer markets); Arun Sundararajan, The Sharing Economy: The End of Employment and the Rise of Crowd-Based Capitalism (MIT Press 2016) (Uber, Airbnb, etc); Jessica SilverGreenberg, 'Perfect 10? Never Mind That. Ask Her for Her Credit Score' New York Times (New York, 26 December 2012) A1 (dating). For detailed analysis of new developments in credit markets, and the intersection with anti-discrimination law, see Noelia Collado-Rogriguez and Uta Kohl, "'All data is credit data": Personalised Consumer Credit Score and Anti-Discrimination Law', this volume.

${ }^{57}$ Donncha Marron, Consumer Credit in the United States: A Sociological Perspective from the 19th Century to the Present (Palgrave Macmillan 2009) 133, 157; Mac Síthigh and Siems (n 55) 1061-4.

${ }^{58}$ Kevin Werbach, 'Panopticon reborn: social credit as regulation for the age of Al' (2020) http://dx.doi.org/10.2139/ssrn.3589804; Mac Síthigh and Siems (n 55) 1048ff.
} 
access to public services as well as public shaming through billboards. The third is perhaps the closest variant on credit scoring, though considerably more innovative, and involves the 'big three' of the Chinese IT industry - Baidu, Alibaba and Tencent, albeit with some doubt in more recent times as to continued cooperation with the People's Bank of China and with public authorities.

We may think of conventional credit scoring - and indeed the current fascination with league tables, rankings, and measuring everything that moves ${ }^{59}$ - as quintessentially reductive, and in some respects the opposite of 'personal'. Yet the centrality of reputation to the 'sharing' economy, and the rapid developments of new systems and services in China, indicate (albeit in different ways and with varying implications) an important realignment of the relationships in how people participate in markets and (in the Chinese examples) the relationship between state and citizen. In some ways, this echoes earlier rationales for systematised credit scoring, in that it allowed each borrower to be dealt with in light of their specific circumstances, eschewing the use of rank or family. ${ }^{60}$ But while this was true to an extent, proxies (including in relation to character) never disappeared, and computerisation in the $20^{\text {th }}$ century supported the use of broader (statistical) measures of risk. ${ }^{61}$

In present-day China, then, we see an old story of character and trustworthiness, but in a new context of commercial and physical access to (e.g.) transport and accommodation; ${ }^{62}$ the emerging importance of the sharing economy to city life - and the involvement of major information industry players in smart city projects - in the 'Western world' could deliver, through less direct means, similar results.

\subsection{Facial recognition technologies}

Even a fair and transparent system using reputational information (or information supporting customisation more generally) is of little use without an extremely reliable way of associating individuals with the correct data. Credit scoring in the US, for instance, was transformed by the use, across organisations, of social security numbers (issued by the US government, but not initially for this purpose). ${ }^{63}$ In smart city projects, facial recognition technologies (FRTs) have emerged as one possible equivalent. FRTs are thus part of many smart city projects; indeed, they are a part of a number of the social credit pilots. ${ }^{64}$ In Toronto, Sidewalk made an new and explicit commitment, in the later stages of discussion, not to use FRTs, addressing criticism from privacy advocates. ${ }^{65}$ Moreover, the desire to deliver efficient and customised services is a key driver of research and development in FRTs, especially as they offer the prospect of delivering personalised services in public spaces or without the more conventional registration or authentication functions that are suitable in certain areas

\footnotetext{
59 Jerry Muller, The Tyranny of Metrics (Princeton University Press 2018); Geoffrey C. Bowker and Susan Leigh Star, Sorting things out : classification and its consequences (MIT Press 1999) 324ff; Wendy Nelson Espeland and Michael Sauder, 'Rankings and Reactivity: How Public Measures Recreate Social Worlds' (2007) 113 American Journal of Sociology 1.

60 Lauer (n 56) 26.

61 lbid 172, 183.

62 Mac Síthigh and Siems (n 55) 1053.

63 Lauer (n 56) 198-9.

64 Mac Síthigh and Siems (n 55) 1050.

65 Moira Warburton, 'Sidewalk Labs' still facing questions over data use in Toronto smart city project proposal' National Post (Toronto, 28 February 2020). For evidence of Sidewalk's earlier interest in FRTs, see e.g. Goodman and Powles (n 26) 491.
} 
of service delivery (e.g. library borrowing, managing one's tax or property affairs) but less so in others. But as these technologies reach the stage of being more widely deployed, especially for real time / 'live' use, it has become apparent that their use, by public or private sector bodies, is provoking controversy - ranging from the concerns over surveillance that have also been aired in relation to CCTV, number-plate recognition, and the like, to criticism of the accuracy of FRTs (including the differential performance of systems in terms of gender and race). ${ }^{66}$

In 2020, this has become one of the higher profile debates regarding law and technology, both in terms of broad (and sometimes normative) proposals but also the specific application of existing measures, especially in data protection law. The two are connected; see for instance the UK Information Commissioner's support for a statutory code of practice, echoing the creation of a Surveillance Cameras Commissioner and associated code under the Protection of Freedoms Act 2012.67 This recommendation is made as part of the ICO's analysis of police use of FRTs, which goes beyond an initial assessment of the lawful basis required (under data protection law) for the use of FRT and sets out a broader concern regarding whether the current combination of laws and codes provide a robust regulatory regime for these technologies.

Judicial and legislative attention is also apparent. In $R$ (Bridges) $v$ Chief Constable of South Wales Police ${ }^{68}$ the Court of Appeal in England and Wales will consider the lawfulness of the use of FRTs by South Wales Police (the national 'lead' for FRT trials, which has been funded by central government to this end). At first instance, the High Court did not find that anything unlawful was taking place: common law police powers in particular were engaged, and article 8 ECHR was not violated, though it was accepted - against the submissions of the police force - that various aspects of data protection and human rights legislation were engaged. A Private Members' Bill has been introduced by a member of the House of Lords, ${ }^{69}$ and a general debate on the subject took place in the House of Commons in January $2020 .{ }^{70} \mathrm{~A}$ number of US cities (including the northern Californian cities of San Francisco and Oakland) have already adopted various prohibitions.

There has been an understandable focus, in media commentary, on what were said to be proposals, from the European Commission, to place a moratorium on the use of FRTs in certain locations. The final version of the Commission's paper (on artificial intelligence more generally, published February 2020) noted the need for a specific and proportionate legal basis under data protection law, and, 'in order to address possible societal concerns relating to the use of Al for [FRT] purposes in public places',

\footnotetext{
${ }^{66}$ E.g. Kashmir Hill, 'Face Scan App Inches Toward End of Privacy' New York Times (New York, 19 January 2020) A1; Steve Lohr, 'Facial Recognition Is Accurate, if You're a White Guy' New York Times (New York, 9 February 2018); Madhumita Murgia, 'The face race' Financial Times (London, 20 April 2019) Magazine 26; Robert Draper, 'They are watching you' (2018) 232(2) National Geographic 30; Woodrow Hartzog, Privacy's blueprint : the battle to control the design of new technologies (Harvard University Press 2018) ch 7.

67 Opinion 2019/01, 'The use of live facial recognition technology by law enforcement in public places' https://ico.org.uk/media/about-the-ico/documents/2616184/live-frt-law-enforcement-opinion20191031.pdf.

${ }^{68} R$ (Bridges) $v$ Chief Constable of South Wales Police [2019] EWHC 2341 (Admin).

${ }^{69}$ Automated Facial Recognition Technology (Moratorium and Review) Bill [HL] 2019-20.

${ }^{70}$ Hansard HC (6 $6^{\text {th }}$ series) vol 670 cols 647-556 (27 January 2020).
} 
called for a 'broad European debate on the specific circumstances, if any, which might justify such use, and on common safeguards'. ${ }^{71}$ If a moratorium of some sort becomes law, it is quite possible that there will be some exclusions (i.e. situations where the tightly regulated use of FRTs is lawful); will this include the delivery of personalised services, or will the emphasis be on security e.g. counterterrorism? If so, which other means of working with individuals on a customised basis will be technologically and commercially feasible?

As other contributors to this volume have commented, there are close links between personalisation and the detection of identity. ${ }^{72}$ In relation to personalised services, then, the resolution of current debates on FRTs is important. One immediate issue will be the scope of any restriction. For instance, the US city of Portland is currently considering whether to focus on police and public authority activity or seek to constrain private sector use of FRTs. More broadly, the use (or disavowal of using) FRTs may be a factor in public reactions to smart city projects, as has already emerged in Toronto.

\section{Conclusion}

The argument that a smart city is a 'more efficient and greener place to live and do business' (to recall an argument from section 2, above) is echoed across the projects discussed in this chapter - though with the efficiency and environmental rationales being emphasised to different degrees throughout. Despite the different contexts of each, though, they all challenge, through the adoption and deployment of various technologies or approaches to data, a $20^{\text {th }}$-century understanding of the role of public authorities. Many obviously municipal services have been delivered in an undifferentiated way, subject in some cases to democratic oversight, and indeed still pursuing environmental and efficiency goals. What we see in this century, though, is a more personalised or customised relationship between states and individuals, driven in some cases by persistent connections and the continuous analysis and combination of data, and often mediated by the relevant technology companies. This amended relationship, then, becomes part of the promise - that the green, efficient city is one that knows its people and deals with them, whether directly or through hypernudges and other means, as individuals.

As such, facial recognition technologies, sensors embedded in flagstones and flagposts, and the traces of scooters and drones flying in three dimensions around a crowded city, all contribute to the reliability of these inchoate personalised interactions. FRTs allow the individual to be recognised - and so to be denied access. Sensors replace inefficient monitoring (or worse, sampling) - but bring the best and worst of the Internet environment into the neighbourhood, street, and even apartment. Mobility data allows cities to do air traffic control on the ground and deliver the best possible advice - if it can be gathered in a way that works across public/private boundaries and with respect for individuals. A city interested in any of these three, or (as is increasingly the case) some combination thereof, must understand how existing laws delimit what is possible, and engage in reasoned debate on new governance arrangements.

\footnotetext{
${ }^{71} \operatorname{COM}(2020) 65$.

72 See Marc Welsh, 'Personalisation, power and the datafied subject', this volume; see also Shoshana Zuboff, The Age of Surveillance Capitalism: The Fight for a Human Future at the New Frontier of Power (Profile 2019) 251-3.
} 
Even so, objections to (for instance) FRTs are not just about an analysis of the specific affordances and use cases of how an image is captured and processed. There is a clear sense of a certain level of unease with the balance of power, with mission creep, and with the ways in which change comes about. The travails of Sidewalk Toronto, for one, serve as an illustration of the centrality of vision and mandate, but also the proper role for public authorities and private companies. And, even the best intentioned of debates may result in temporary bans or self-denying ordinances, focused on specific iterations rather than the whole. If we debate FRTs or reputational scores as inherently good or bad, without attending to the contexts in which they are used (such as personalised services), we run the risk of avoiding more challenging questions about the shape of the future city.

In this chapter, I have sought to show how success in the smart city depends not just on the development of new technologies, but the careful identification of relevant goals (e.g. sustainable forms of mobility), the trade-offs that might be necessitated, and the governance mechanisms that must be put in place (whether the project is delivered by a public body or otherwise). Compliance with data protection or privacy law is part of that route to success, but compliance alone does not bring public confidence - let alone provide the conditions for a genuine debate on how technology, and the collection of personal and non-personal data, can be used to improve quality of life. ${ }^{73}$ Predictions about the future are notoriously unreliable - especially in relation to urban living - but expectations and objectives can engage residents in a debate about how personal they want their interactions with public authorities to be, and how data can be properly managed. Such debates can and should encompass technologies not currently on the mass market (e.g. autonomous vehicles) and systems that are at an advanced stage of development in different political contexts (e.g. the Chinese social credit systems). At a time when a healthy scepticism regarding the turn-of-the-century apparent consensus on the liberating power of technology and the Internet has come to prominence, a return to urbanist utopian thinking of earlier decades, regarding the shape of the city rather than the technology, with municipalities and their understanding of the public good as a key voice, might allow personalised services to emerge and command trust and legitimacy, unlocking the efficient and sustainable city of the future.

\footnotetext{
${ }^{73}$ In this regard, I share the reservations as to the ability of legal measures protecting privacy to do the task of regulating markets, set out elsewhere in this volume: TT Arvind, 'Personalisation, markets, and contract: The limits of legal incrementalism', part III.
} 